\title{
Failure of the Collection Volume Method and Attempts of the ESE Lightning Rod Industry to Resurrect it
}

\author{
Abdul M. Mousa* \\ Consultant (Retired from BC Hydro), Vancouver, Canada
}

\begin{abstract}
To facilitate the marketing of their devices, the vendors of Early Streamer Emission (ESE) lightning rods are attempting to get the Collection Volume Method (CVM) in IEEE Standard 998 which deals with the Shielding of Substations. This attempt follows their failures before IEC, Standards Australia and the NFPA (National Fire Protection Association). Voting on the standards of the IEEE is done by a pool of persons, most of whom are not lightning experts. The same applies to potential buyers of ESE devices who are being wooed by use of the CVM. This paper seeks to enlighten those persons by using indisputable field observations to prove invalidity of the CVM. The paper also shows that development of the CVM rested on a false perception that discrepancies existed between field observations and predictions of the Electrogeometric Model (EGM), and that the CVM failed to address those claimed discrepancies.
\end{abstract}

Keywords: Lightning, lightning protection, lightning protection standards, collection volume method, electrogeometric model, early streamer emission (ESE) lightning rods.

\section{INTRODUCTION}

While its roots go further back in history, the Electrogeometric Model (EGM) was first articulated by Young et al. in 1963 [1]. An important subsequent paper by Sargent [2] showed that the EGM predicts an increase in the median amplitude of the collected lightning strokes with increase in height of the structure. Sargent also showed that the median stroke amplitude depends on shape of the structure (mast versus wire).

During the late 1970's, Eriksson [3] incorrectly thought that predictions of the EGM were contradicted by field observations. His main criticisms were the following:

a) That field observations for a wide range of structure heights appeared to give an almost constant median value of the amplitude of the collected strokes, and;

b) That the EGM presumes that the striking distance is correlated to amplitude of the return stroke while measurements revealed a wide dispersion.

Eriksson $[4,5]$ hence developed the model which became widely known as the Collection Volume Method (CVM) in the hope of curing the above perceived shortcomings. He also proposed that a frequency distribution of stroke amplitudes having a median value of $31 \mathrm{kA}$ (the so-called "CIGRE Distribution") be adopted for all structure heights up to $60 \mathrm{~m}$, as well as for the strokes to flat ground [6].

But Melander [7] showed that the measurements taken on Eriksson's mast, upon which most of his research was based, were flawed; as he took the measurements at base of the mast instead of its top. Melander's observation regarding

*Address correspondence to this author at the Consultant (retired from BC Hydro), Vancouver, Canada;

Tel: 1-604-941-0793; Fax: 1-604-941-0793;

E-mails: abdul_mousa@hotmail.com, abdul.mousa@ieee.org effect of location of the measuring point on magnitude of the current was subsequently confirmed by the observed differences between the simultaneous current measurements taken at different heights of the $540 \mathrm{~m}$ Ostankino TV tower in Moscow [8]. Also, critics showed that the CVM suffered from the same shortcomings which Eriksson thought existed in the EGM. Further, Eriksson's so-called "Improved EGM" constituted no improvement as it complicated the design of shielding systems without offering any compensating advantage [9].

It was shown that Eriksson erred in interpreting field observations $[10,11]$ and that predictions of the EGM can be reconciled with field observations by making minor rational revisions $[12,13]$. Mousa also showed that Eriksson's/ CIGRE's frequency distribution of stroke amplitudes was poorly defined [14].

In connection with the above, it should be noted that, to date, the IEC standard on lightning protection continues to use the EGM. Also, a survey done by the IEEE in 1992 determined that no power company applied the CVM to the shielding of substations [15]. This finding was again confirmed by a survey that was done by IEEE Working Group D5 in 2007.

However, Rick Gumley, an Australian manufacturer of Early Streamer Emission (ESE) lightning rods, realized that the CVM provided an alternative way of justifying the claim that a single air terminal can protect a whole building. The trick in commercializing the CVM is in exploiting the "field intensification factor" of Eriksson's model [11]. In this connection, it should be noted that Gumley used a proprietary software named BENJI to apply the CVM to his ESE device called the "Dynasphere".

The use of the CVM to justify ESE design practice was low key in the beginning as vendors focused their efforts on getting ESE theory sanctioned by standards organizations. Their first success was in France and it was rather easy as the 
French system enabled manufacturers within a given sector to issue standards if they agreed among themselves, and without scrutiny by independent scientists. On the other hand, their attempt to expand into the USA, by applying to NFPA (National Fire Protection Association), raised stiff opposition as the scientific community at large made its position known [16].

After a bitter decade-long dispute, NFPA refused to issue a standard for ESE devices. This gave the word "ESE" bad connotations. As a result, some vendors changed the names of their devices, and the interest in using the CVM as a commercial promotion tool was resurrected. In connection with the above, it should be noted that Mousa [17, 18] was quick to recognize vendors' promotion of the CVM as a back door to legitimizing ESE technology. Recently, Hartono and Robiah [19] went further by renaming the subject technology "ESE/CVM devices".

In recent years, the promotion of the CVM via the publication of papers has been intensified. The paper by Gumley and D'Alessandro [20] is an example of such works. Independent scientists have responded by documenting their reservations regarding the CVM [21-25].

Today, ESE vendors in Europe are fighting to prevent their standard from being withdrawn by CENELEC. In North America, on the other hand, the main thrust of ESE vendors has been on getting the CVM sanctioned by IEEE Standards Association, namely via Working Group D5 which deals with the shielding of substations. In this connection, it should be noted that unsuccessful attempts were previously directed against Standards Australia and the NFPA.

The attack on the IEEE is spearheaded by ERICO who is promoting the CVM as an "improved model" that is "modern" and "cost-effective". The objectives of this paper are as follows:

a) Presenting the proof regarding invalidity of the CVM in terms which non-specialists can understand, namely, the contradiction of the CVM with field observations.

b) Documenting the fact that development of the CVM rested on false perceptions regarding shortcomings of the EGM, it failed to accomplish its intended objective, and that the EGM was revised long ago to eliminate the discrepancies which Eriksson thought existed between its predictions and field observations.

c) Making the scientific community aware of the imminent danger to national and international standards that is posed by the ongoing proceedings before IEEE Working Group D5.

\section{FAILURE OF THE CVM}

A great deal of the criticism against the CVM has been based on physics and theoretical grounds. This paper uses a different approach by showing the contradictions between the CVM and indisputable field observations. Hopefully, this will bring the facts within the grasp of a wider audience.

The following discussion shows that the CVM contradicts field observations regarding the following: a) the assumptions upon which it is based, b) its estimates of the striking distance, c) its predictions regarding effectiveness of the shielding that it provides, and, d) the way the model was constructed, namely its elimination of the ground plane.

\subsection{Invalidity of the Assumptions Upon which the CVM is Based}

It has been known for a long time that most cloud-toground lightning discharges are of the negative polarity, and that the related channel is branched. On the other hand, negative impulses in the lab did not produce branches.

Schonland [26] believed that the above discrepancy arose from the existence of non-uniform charge in the space between surface of the ground and base of the cloud. To test that hypothesis, nails were attached to the ground plane so as to generate corona. Upon repeating the lab tests, the negative impulses produced branching, same as the case of natural lightning discharges.

As the above indicates, it has been known since 1931 that the reason lightning behaves the way it does is the existence of randomly-distributed space charge in the atmosphere. That charge guides the development of the lightning channel over most of its path. That is why the lightning channel usually takes a zigzag shape.

In summary, the development of the lightning channel is governed by two forces: a) the charges on the downward leader (and in the cloud), and, b) randomly-distributed space charge. The CVM does not take the space charge into consideration, and that is one of the main reasons why it produces erroneous results.

It is the omission of the space charge in the CVM that makes the height of the cloud, the charge in the cloud, and the charges in the upper part of the leader appear to be significant to the lightning attachment process, when in fact they are not. This leads to an absurd conclusion, for how would it sound if designing the lightning protection of an installation, say a power line, required knowledge of the height of the clouds in the area where the line has been built?

In connection with the above, the following should be noted:

a) J.G. Anderson (private communication, 31 January 2002) used EPRI software STROKE8 to investigate the effect of space charge. He found that the CVM's prediction that the downward leader bends toward the charges on the wires of the power line, and the resulting increase in the attractive radius with height, becomes negligible when the downward leader is assumed to "wiggle" as seen in lightning photos.

b) Szpor [27] commented: "Theories predicting a rectilinear leader's path do not conform to nature".

c) As noted by Golde [28] after Berger, the electric fields at ground level under an active thunderstorm are notably lower than those which result from the assumption of an undisturbed electric field between the known cloud charges and earth. Citing Wilson, Golde states that this must be due to the presence of positive space charge between cloud and ground. This is confirmed by the simultaneous measurements taken by Rust and Moore [29] in which the magnitude of 
the electric field at ground level was found to be significantly smaller than the electric field aloft.

\subsection{Striking Distance Discrepancies}

A crucial feature of the CVM is that it gives striking distances that far exceed those used in the EGM. The CVM also implies a large dependence on height of the structure. The invalidity of the estimates of the CVM has now been proven by the measurements obtained by Miki et al. on $80 \mathrm{~m}$ tall $500 \mathrm{kV}$ double circuit towers using high speed cameras [30]. Please see Fig. (1).

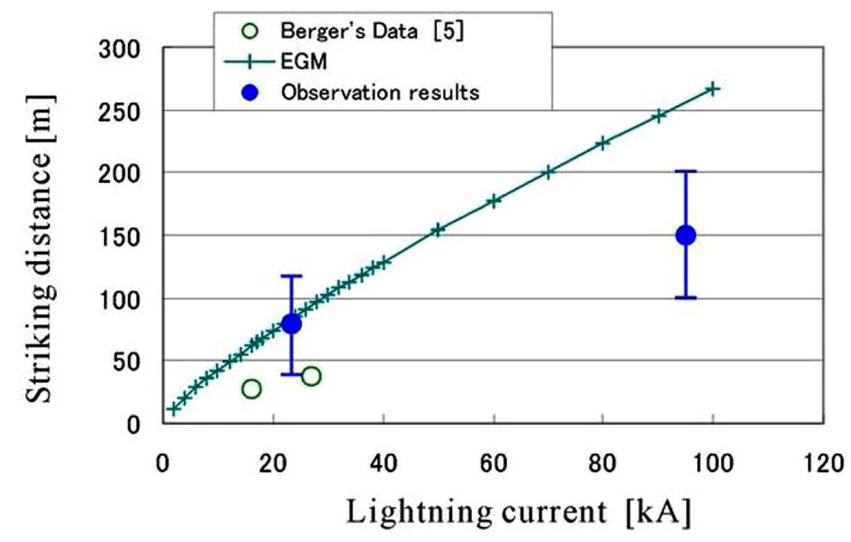

Fig. (1). Striking distances measured on power lines.

\subsection{Lightning Strikes to Points below the Tops of Tall Structures}

The CVM implies that a tall tower cannot be struck below its top. This prediction of the CVM rests on two of its aspects that make the striking distance to the peak of the structure much larger than that to points below the top, namely: 1) The claimed large effect of height on the striking distance, and; 2) The field intensification factor which is huge for the pointed peak [31] and drops to 1.0 (or less) for any point on a flat side surface of the structure.

The above prediction of the CVM is contradicted by many field observations, some of which are listed hereafter:

1) Fig. (2), which shows a lightning strike to the Washington Monument in USA, is one of the best photos of strikes to points below top of a structure [32]. Note that the stroke terminated on a flat surface at a point well below the pointed peak where the lightning rod is located. The height of the monument is $169.3 \mathrm{~m}$ and it is built of marble, granite and sandstone. The photo indicates that the struck point was at least $40 \mathrm{~m}$ below the top.

2) Golde [33] reported that the $230 \mathrm{~m}$ high Palace of Culture in Warsaw, Poland, was struck at a platform located $95 \mathrm{~m}$ below its top. This is schematically depicted in Fig. (3).

3) The $\mathrm{CN}$ Tower in Toronto, Canada, was reported to have been struck below its top [34].

4) The railing of the uppermost platform of one of Berger's masts was struck by lightning [33]. An unrelated streamer from the top simultaneously appeared in the related photo, same as in the above photo of the Washington Monument.

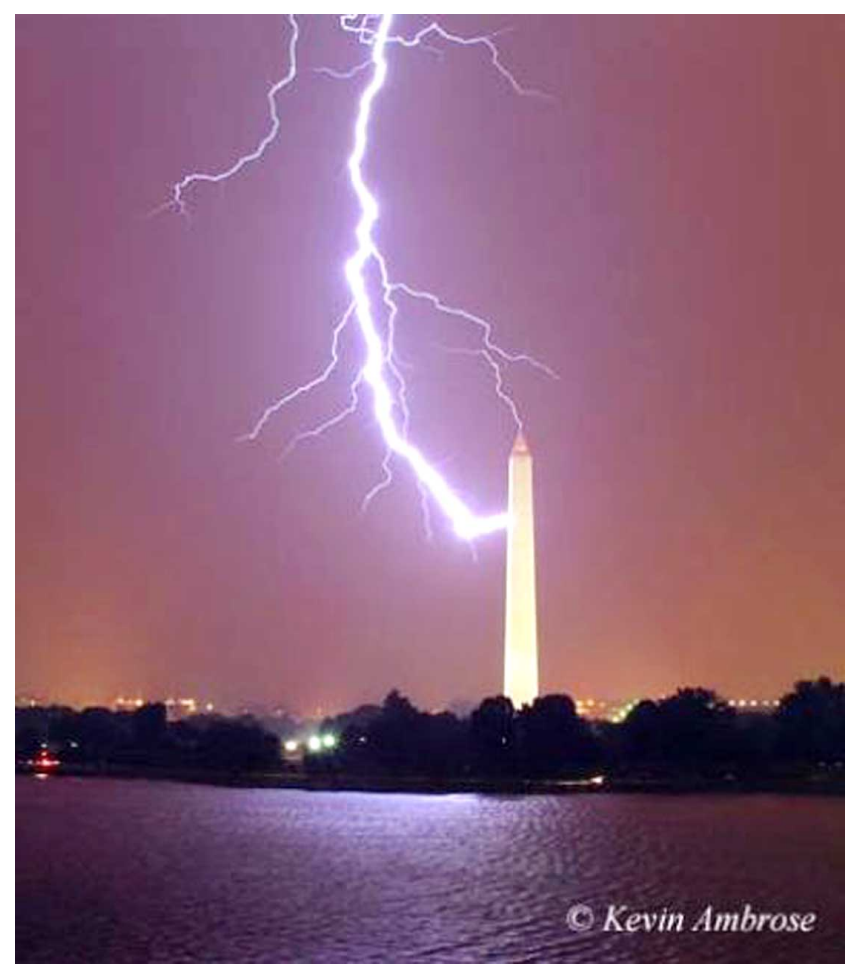

Fig. (2). A lightning strike to the Washington Monument.

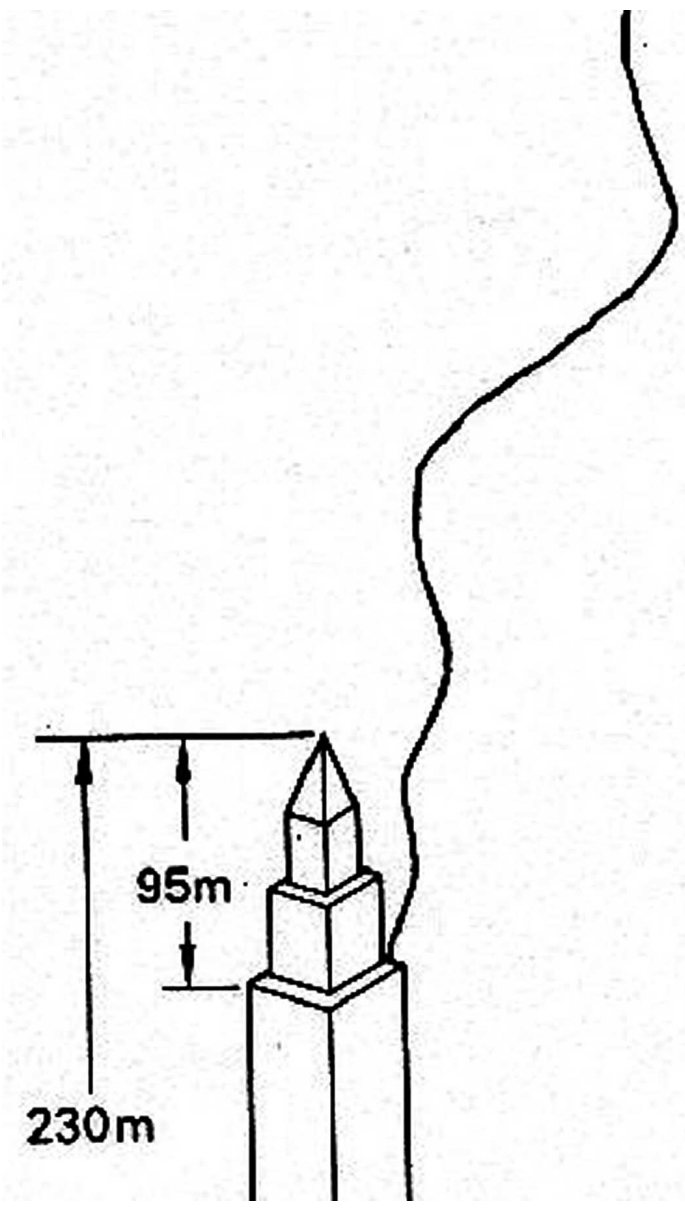

Fig. (3). A lightning strike to the Palace of Culture, Warsaw, Poland. 
5) The $540 \mathrm{~m}$ high Ostankino TV tower in Moscow was reported to have been often struck at points below the top [35]. The lowest struck point (at the $325 \mathrm{~m}$ elevation) was $215 \mathrm{~m}$ below the top.

6) Golde [28] reported after H.M. Towne that the side elevations of the Empire State Building were struck by lightning, and that one of the struck points was located $50 \mathrm{ft}(15 \mathrm{~m})$ below the top.

7) Hartono \& Robiah reported a lightning strike to a point about $30 \mathrm{~m}$ below the top of a $116 \mathrm{~m}$ minaret of a mosque in Putrajaya, Malaysia. The minaret was equipped with an ESE device. Please see figure 7 of [18].

8) Krider et al. [36] reported an unusual case in which lightning struck one of the three guy wires that support an $80 \mathrm{~m}$ TV tower. This was reproduced on page 106 of Uman's book [37]. Please see Figs. $(4,5)$ herein. The struck point was $14 \mathrm{~m}$ below the top and $5 \mathrm{~m}$ horizontally from the axis of the tower. The photo shows an upward leader emanating from top of the tower, similar to what was noted above for both the Washington Monument and Berger's mast. Krider suggested that the upward leader was likely induced by an unrelated (nearby) lightning strike. In this connection, it should be noted that three separate flashes were captured in the photo and that the total exposure time was 2 minutes. The following discussion of Krider's photo provides analytical proof of the failure of the CVM.

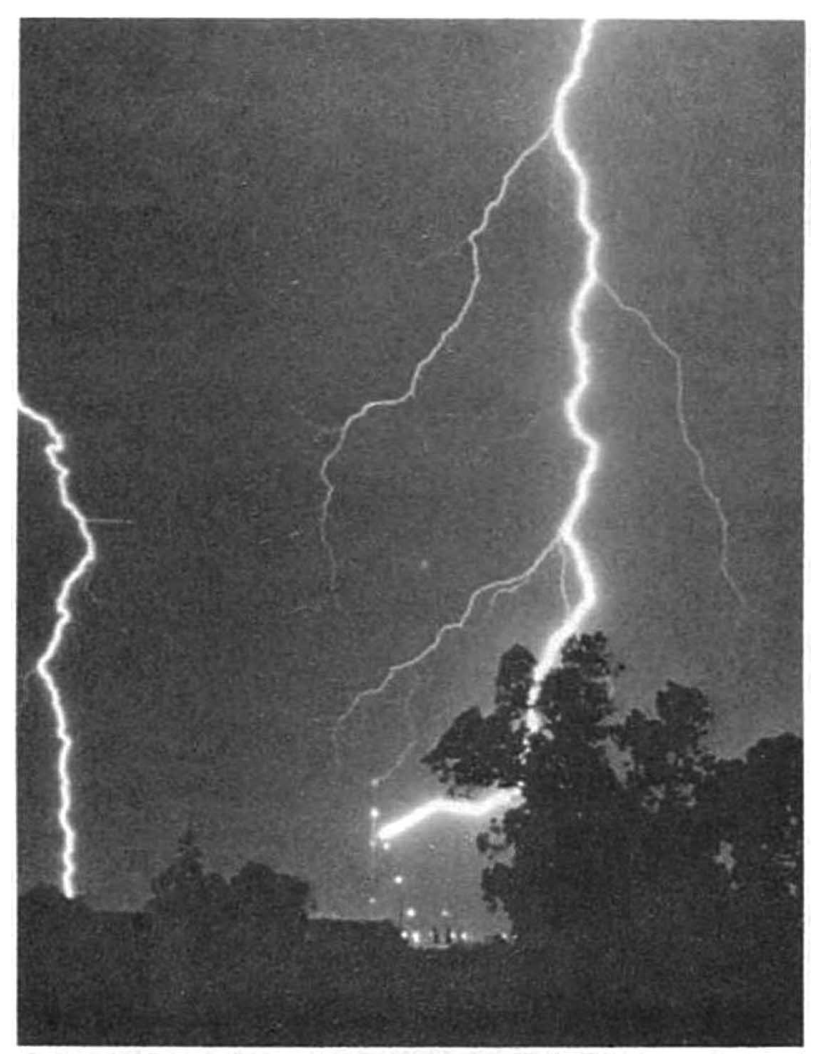

Fig. (4). A Lightning strike to the guy wire of TV tower.

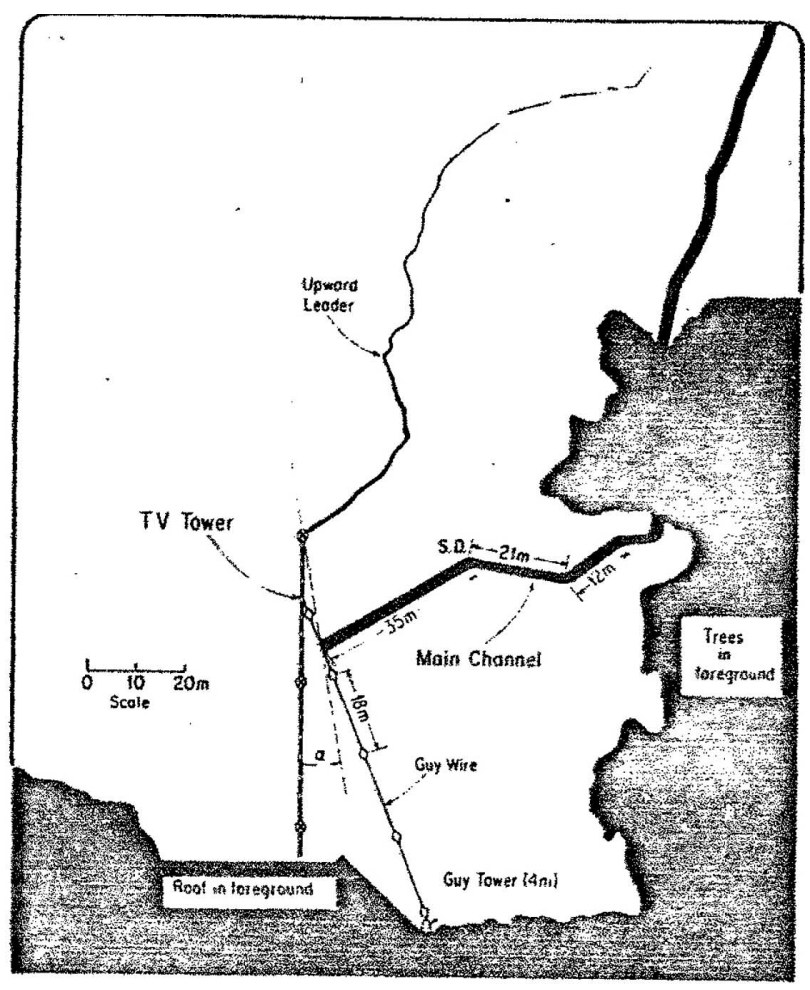

Fig. (5). Geometry of the lightning strike of Fig. 4.

According to Eriksson [12], the attractive radius of the tower is given by:

$R_{t}=0.84 H^{0.6} I^{a}$

where,

$a=0.7 H^{0.02}$

Substituting $\mathrm{H}=80 \mathrm{~m}$ gives

$$
R_{t}=11.645 I^{0.764}
$$

Eriksson takes the attractive radius of a wire to be $80 \%$ of that of a tower having the same height. Hence the attractive radius of the guy wire (diameter $=1.2 \mathrm{~cm}$ ) would take the form:

$$
R_{w}=0.67 H^{0.6} I^{a}
$$

Substituting $\mathrm{H}=66 \mathrm{~m}$ gives:

$R_{w}=8.276 I^{0.761}$

It is a characteristic of shielding geometry that only strokes less than a certain value, say $\mathrm{I}_{1}$, can strike the protected object. In that case, the related protective circles just touch each other without overlapping. In view of the $5 \mathrm{~m}$ horizontal offset of the struck point of the wire relative to the axis of the tower, current $I_{1}$ is governed by the equation:

$\mathrm{R}_{\mathrm{t}}-\mathrm{R}_{\mathrm{w}}=5.0$

Substitution from (3) and (5) in (6) gives: $\mathrm{I}_{1}=1.7 \mathrm{kA}$

Based on the above, the CVM implies that the stroke of the flash must have been less than $1.7 \mathrm{kA}$. This is obviously 
incorrect for the following reasons: 1) The luminosity and branching of the flash in Fig. (4) indicate that the current was substantial, say $10 \mathrm{kA}$ or larger. 2) Based on theoretical considerations, Cooray [38] found the minimum stroke amplitude to be $2 \mathrm{kA}$. 3) Based on available measurements, Krider et al. [39] found the minimum current of first negative strokes to be $3 \mathrm{kA}$. 4) Capturing three flashes within 2 minutes in a single photo indicates that the storm was intense at that moment. Hence the current could not have been less than $1.7 \mathrm{kA}$.

Note that, for a given stroke amplitude, the CVM overestimates both the striking distance and the protective radius. It follows that, for a given protective radius, the CVM underestimates the corresponding stroke amplitude. This explains why the above analysis gave an unrealistically low current.

Note that Eriksson assigned a field intensification factor equal to 60 to a $60 \mathrm{~m}$ high mast [3]. Hence a value at least this high should apply to the above $80 \mathrm{~m}$ TV tower. Note also that the CVM assumes the field intensification factor for wires to be about $80 \%$ of that of a mast having the same height, and this is reflected in equations (1) and (4) above. Hence the field intensification factor for the guy wire would be about 40 . On the other hand, the field intensification factor for a point on a vertical flat surface would be only 1.0 (or less).

The failure of the CVM to explain the strike to the above guy wire, where the field intensification factor is presumed to be about 40, shows that the CVM implies that it would be impossible for the side of a tall tower to be struck at a point below the top. This contradiction between field observations and the CVM proves its invalidity. The same applies to the Field Intensification Method which is a slightly modified version of the CVM $[17,18]$.

\subsection{Other Observations Proving Invalidity of the Claimed Zone of Protection of the CVM}

1) The use of a single ESE lightning rod to protect a whole building was initially based on the claim that ESE devices have some "magic powers". When that claim was subsequently dropped, the same practice of using a single air terminal to protect a whole building was maintained but then justified by the CVM. On the other hand, Hartono [19] proved the ineffectiveness of the subject devices by extensive documentation of lightning strikes to the related buildings. Some of those strikes occurred very close to the locations of the air terminals. Hartono's evidence equally proves the invalidity of the CVM, same as it proved the invalidity of the prior claim regarding the capabilities of ESE devices.

2) Present lightning protection codes, which are based on the Rolling Sphere Method / EGM, imply the need for many Franklin rods to protect any of the buildings for which a single ESE-CVM device is applied by their vendors. Buildings protected by Franklin rods do experience some lightning strikes / bypasses and the reason is known: the striking distance of those strokes must have been less than the $45 \mathrm{~m}$ (about $150 \mathrm{ft}$ ) radius of the Rolling Sphere upon which the design was based. The vendors of ESE devices previously raised an uproar regarding the above occasional failures of Franklin rod systems. However, it should be noted that those undisputed failures imply that many more failures / bypasses would occur if the number of air terminals was drastically reduced as proposed by the CVM. Also, if the CVM was applied to a system designed according to the Rolling Sphere Method, the CVM would indicate that the system is over-shielded and that no bypasses can occur. This contradicts field observations and it proves the invalidity of the CVM.

3) ESE devices were developed as a replacement for radioactive lightning rods after the latter type was banned on the grounds that the claimed benefit did not justify the related nuclear pollution. It has been shown that lightning struck the buildings that were presumed to be protected by radio-active lightning rods and that those devices are not effective [33]. A single radio-active lightning rod was used per building, same as the current practice for ESE devices. Hence radio-active lightning rods can be considered to be air terminals placed in accordance with the CVM. It follows that the failures of radio-active lightning rods also prove the invalidity of the CVM.

\subsection{Discrepancy Regarding Construction of the Model}

Eriksson [5] described strikes to ground as a "default condition" which arises when the structure under consideration fails to intercept a stroke. The elimination of the ground plane was apparently a consequence of adopting concepts that are not applicable to the ground plane, namely:

a) Describing the strike process as termination on an electrode having a specific critical radius. Obviously, no such value can be assigned to a flat surface.

b) Describing the formation of the upward leader in terms of a field intensification factor governed by the ratio of the height to diameter of the struck object. Again, no such ratio can be assigned to a flat surface.

In their discussion of the CVM, Hileman, Whitehead, Mousa and Srivastava [9] criticized the elimination of the ground plane as it implies that strikes to ground do not involve the generation of upward leaders. On the other hand, as far back as 1934, photographs have shown that upward leaders/streamers occur from flat ground. Please see figure 34 of [40]. Since then, other photos of upward leaders emanating from the ground have been obtained, including the following: a) the Boys' camera photo that was documented by Golde [41] of a case in which the striking distance was about $50 \mathrm{~m}, \mathrm{~b})$ the 1975 photo by Krider and Ladd [42], and, c) the photo in Fig. (6) which was taken by a French storm chaser.

(source: http://membres.lycos.fr/joose/cha ssorages1.jpg).

\section{RESOLVING THE PERCEIVED DISCREPANCIES OF THE EGM}

The work done by Mousa and Srivastava during the 1980 's to reconcile predictions of the EGM with field observations is briefly summarized hereafter.

1) The perception that some of the measured striking distances were excessive was shown to arise from 
error in identifying the striking distance from the photographs. Specifically, the return stroke of a cloud-to-cloud or cloud-to-ground lightning discharge induces an upward leader from the top of any nearby tall tower. In this connection, it should be noted that Warner recently provided photographic evidence that a lightning strike-to-ground induced upward discharges from several tall towers located about 12 $\mathrm{km}$ away [43]. If a downward lightning flash occurred while such an unrelated upward leader is still conductive, then it will terminate at its tip instead of striking the peak of the tower itself. An error could then occur in identifying the striking distance from still photographs. The above mechanism was shown to apply to one of the photos taken by Eriksson himself [10].

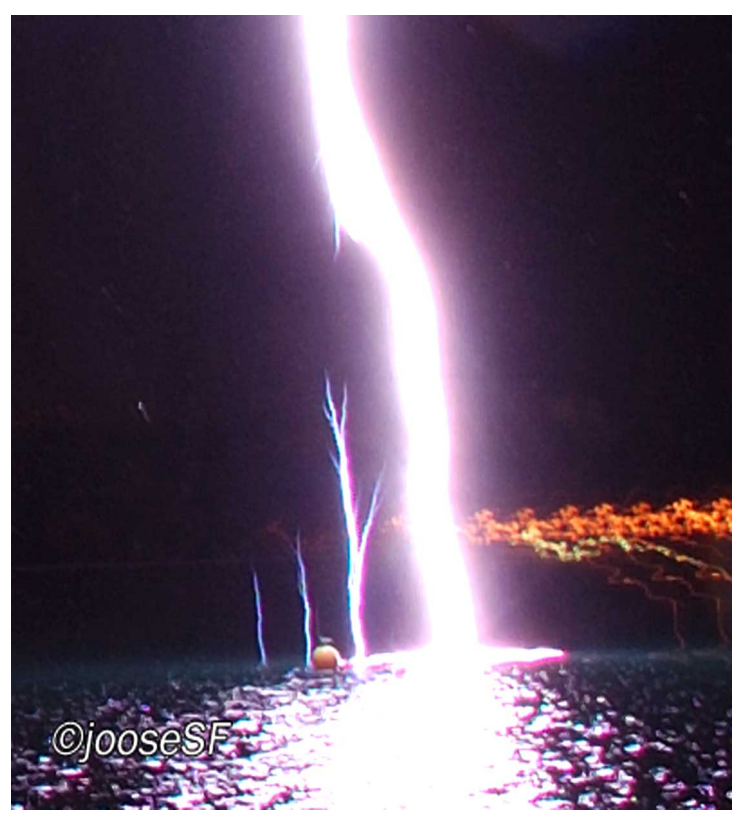

Fig. (6). Upward leaders emanating from the ground.

If the downward leader in the above case terminated instead at a point below the top of the tall tower, then the photo would simultaneously show the existence of the unrelated upward streamer emanating from top of the tower. Three such photos were mentioned above, and Professor Krider's alternative explanation of the subject upward leader [36] agrees with that of Mousa [10].

2) The median current to flat ground $I_{g}$ was thought to be only $13 \mathrm{kA}$ at the time when Sargent [2] did his analysis. Mousa \& Srivastava [11] showed that underestimating $I_{g}$ causes the effect of height on the median current of the strokes collected by the structure $\left(\mathrm{I}_{\mathrm{s}}\right)$ to be exaggerated. On the other hand, when a proper value of $I_{g}$ is used, the effect of height on $\mathrm{I}_{\mathrm{s}}$ becomes small. Also, the difference between $\mathrm{I}_{\mathrm{s}}$ and $I_{g}$ becomes relatively small. On the other hand, Mousa and Srivasatava confirmed Sargent's finding that the value of the median current for towers $\left(\mathrm{I}_{\mathrm{t}}\right)$ is significantly larger than that for horizontal wires $\left(\mathrm{I}_{\mathrm{w}}\right)$.
3) In the case of towers where upward flashes do not occur, measurement errors, error in normalizing the data to a common ground flash density/keraunic level, and errors due to the incidental shielding from other surrounding objects can mask the small effect of height on the median amplitude of the collected strokes. That was the cause of the false perception that height had no effect on the median current.

4) In case of power lines, the false perception regarding the effect of height on the median current arose from the gross simplification in simulating the power line by a set of horizontal wires. In real life, the power line consists of both towers and sagged wires, and the median current to each component is different. The net median current for the whole line is governed by both the above values of the median current, as well as by the percentage of the total strokes that terminate on the towers.

5) In view of the above, the effect of height of the power line on its net median current can only be determined from a 3-D model that includes both the towers and the sagged wires. When this was done, Mousa \& Srivastava $[12,13]$ found the net median current to be practically independent of the height. One of the related aspects is that larger heights are associated with higher voltage lines and the spans for these are usually longer. This in turn contributes to changing the percentage of the total strokes that terminate on the towers.

\section{CIGRE'S FREQUENCY DISTRIBUTION OF STROKE AMPLITUDES}

As a corollary of the above, Mousa [14] found the frequency distribution of stroke amplitudes, which was developed by R.B. Anderson and Eriksson and became known as the CIGRE Distribution [6], included the following errors:

1) The portion of the data obtained on Eriksson's mast was in error based on the findings of Melander [7] and others [8].

2) Eriksson lumped data from towers with those from power lines without regard to the effect of shape of the object on the median current.

3) In the case of tall towers where a large percentage of upward flashes occurs, some potential downward flashes will be aborted. This in turn affects the median value of the collected downward flashes.

4) Incidental shielding, e.g. existence of shorter structures or trees in the vicinity, applies to many of the tall towers on which the data was collected. This may have skewed the frequency distribution of the collected strokes.

5) Measurements for both positive and negative strokes were included in the same data set, and it may not have been possible to identify each type.

6) In line with his opinion that height had no effect on the median current, Eriksson lumped data from masts of different heights without discrimination. 
7) The data included some measurements based on a 2 kA lower sensitivity threshold while others were based on a $5 \mathrm{kA}$ threshold.

8) Some of the data included readings caused by induction from nearby strokes rather than from direct strokes.

9) Further to the above, Mousa concluded that Eriksson erred in suggesting that the frequency distribution of stroke amplitudes to structures should be taken as being also applicable to strokes to flat ground. The latter value was found to be $24 \mathrm{kA}$, which is about $20 \%$ less than the about $30 \mathrm{kA}$ value that applies to transmission lines.

\section{FAILURE OF THE CVM TO CURE THE CLAIMED DISCREPANCIES}

As stated in the INTRODUCTION, Eriksson's model was developed in response to perceived discrepancies in the EGM. But the CVM failed to address those claimed discrepancies. Specifically,

1) Eriksson's equations for the attractive radius, which are reproduced above, do imply dependence of the median current of the collected strokes on height of the structure. They also imply that the strikes to flat ground should have a lower median value than that measured on structures.

2) The subject equations similarly presume a correlation between the striking distance and amplitude of the return stroke.

The above points were previously raised in 1987 by Mousa, Srivastava and others [9].

\section{UNJUSTIFIED CLAIMS OF SUCCESS OF THE CVM}

Eriksson [4, 5] claimed agreement between field observations and predictions of the CVM. Those claims were unjustified, and this was pointed out by Mousa and others [9] in their discussions of Eriksson's work. Some examples follow:

1) To decrease the required shielding angle, Eriksson arbitrarily used a conductor height equal to only $60 \%$ of height of the tower. Whitehead's EGM, on the other hand, uses the height of the wires at the points of attachment to the tower.

2) There is a critical stroke current $I_{c}$ below which strokes to an energized wire are harmless as the resulting surge is below the withstand voltage of its insulation. Where the shielding is not perfect, strokes up to a higher value $I_{1}$ can penetrate the shielding system. The correct number of shielding failures is obtained by integrating the "exposure arc" over the current range $I_{c}$ to $I_{1}$. Eriksson. on the other hand, took all the strokes to the whole line that fall in the range $I_{c}$ to $I_{1}$ as causing shielding failures. As pointed out by Mousa and others [34], the above approach has no physical basis.

3) In comparing his method to Whitehead's EGM, Eriksson mixed the definitions of striking distance and attractive radius despite these being different physical quantities.

Eriksson assigned arbitrary "effective heights" to Berger's masts to make them fit into his equation regarding effect of height on the ratio of upward flashes.

\section{RESPONSE TO THE ATTACKS ON THE EGM}

IEEE Standard 998 presently uses the EGM, same as the lightning protection standards of the IEC and other organizations, and the objective of ERICO's attack is to get this replaced by the CVM. Also, in their previous failed attack on NFPA Standard 780, ESE vendors claimed that the EGM was obsolete and should be replaced by the Leader Progression Model (LPM).

Of course, the EGM will eventually be replaced by another model that is more accurate, yet simple enough to enable lightning protection practitioners to use it in every day applications. The accuracy of that replacement model has to be validated via field observations, at least as was done for the EGM by Whitehead et al. [44]. If the new model predicts an increase in the striking distance with increase in height of the structure beyond what is evident from lab flashover tests on long air gaps, then this has to be verified via striking distance measurements. Being invalid, the CVM is not a candidate for replacing the EGM. Nor is the LPM.

As discussed above, non-uniform space charge exists in the space between base of the cloud and surface of the ground. That space charge governs the development of the lightning channel over most of its route, and they blind it to the existence of ground objects. This is evident from the zigzag shape of the channel which is seen in lightning photos. Same as the CVM, the LPM does not take that space charge into consideration. Being one of the two major forces that shape the lightning channel, ignoring the space charge cannot lead to better accuracy regardless of any related refinements in describing the interception process.

The EGM takes the effect of the space charge into consideration by assuming that "the leader develops unaffected by the existence of ground objects until within striking distance from the ground object". That assumption is obviously valid over most of the route of the downward leader. However, it is possible that interaction between the downward leader and the ground object starts at some point prior to reaching the final jump condition.

Mazur et al. [45, 46] adopted a reasonable compromise by assuming that interaction between the downward leader and the tower starts when tip of the downward leader is within $200 \mathrm{~m}$ from top of the tower. Based on this, the limited analysis done by Mazur et al. indicates that the effect of height of the tower on the striking distance is rather small. Some related remarks follow:

1) The limited range of variation of the striking distance with height of the tower which is used in the Revised EGM of Mousa and Srivastava [13] rests on the gap factor which is deduced from the observed behavior of long sparks in air gap tests. Such a rational conservative approach is appropriate for use in lightning protection standards unless and until field observations prove the existence of larger dependence of the striking distance on height of the structure. Such observations, if taken on 
masts, should not be arbitrarily extended to wires and/or buildings without adequate justification. So far, the only available extended measurements are those taken by Miki et al. [30] and they do not support the CVM.

2) Omitting the space charge is not the only major source of error in the CVM. Another major error is that it calculates the electric field by multiplying the unperturbed values by huge intensification factors. For example, Eriksson used a factor of 60 for his $60 \mathrm{~m}$ high mast. This implies that the final jump condition would be reached when the unperturbed field reaches just 0.5 $\mathrm{kV} / \mathrm{cm}$. This would occur while the downward leader is still far away. As a result, the CVM exaggerates the attractive radius of a structure or an air terminal.

3) Several other recent models also omitted the space charge, e.g. those by Dellera et al. [47], Rizk [48], Becerra et al. [49], etc. Hence, while the above works advance our knowledge of lightning, the author shares Professor Pedersen's opinion that they are not yet ready for implementation in standards [23, 24].

\section{VENDORS' REPEATED ATTEMPTS TO GET THE CVM IN STANDARDS}

Promoters of flawed theories do not seek the judgment of expert groups as they know that their claims would not stand scrutiny. In this connection, it should be noted that ERICO reneged on a promise that it made during ICLP 2002 in Cracow to provide a copy of its CVM software for evaluation. Instead, vendors try to gain legitimacy through standard organizations where the process is usually administrative rather than technical, many of the involved persons are not experts, and voting within the subject small groups can be manipulated.

The attempts of the vendors of ESE devices to push the CVM through standards organizations are summarized hereafter:

1) An unsuccessful attempt was made to get the CVM in the IEC Standard [22].

2) During 2002, an attempt was made to get the CVM in the Australian Standard. The secrecy surrounding the development of draft standards, together with the influence of the vendors, enabled them to get the FIM (Field Intensification Method), in the draft standard. (The FIM is a slightly modified version of the CVM.) However, upon opening the door for public comments, the intervention by the scientific community led to the removal of the FIM from the standard. The role of the Scientific Committee of ICLP was especially helpful in that respect $[23,50]$. The vendors then sought to get the FIM included in an informative appendix, but that attempt also failed. The FIM has since been abandoned and vendors subsequently resumed promoting the CVM.

3) During January 2003, just three months after the rejection by Standards Australia, ERICO attempted to get its CVM in NFPA Standard 780. ERICO's submission failed to mention the related September 2002 ICLP discussions, nor the rejection by Standards Australia. When those facts became known and the scientific community intervened [51], NFPA rejected the 2003 CVM proposal.
4) The review cycle of Standard NFPA 780 is rather short. This opened the door for ERICO to quickly resume its attempt to get the CVM in the NFPA standard. Its second attempt failed during the 2006-2007 cycle.

5) ERICO then turned its attention to IEEE Standards Association. Working Group (WG) D5, which is in charge of the substation shielding standard No. 998, was easy to mislead as its members are mostly substation designers with little expertise in lightning. ERICO managed to influence the standard development process by getting one of its employees to become secretary of the WG despite the fact that ERICO neither designs nor owns substations. The vendors also succeeded in stacking the membership with many of their employees and supporters. With the vendors funding the persistent attendance of their staff and agents while independent parties not able to do so, attendance at WG meetings has been dominated by vendors' forces. This gave them the voting majority needed to get the CVM into the draft standard.

6) During August 2011, draft IEEE Standard 998 was balloted by a pool of the members of IEEE-SA. While this generated a large number of dissenting comments, ERICO's supporters claimed that the draft received strong approval rate. It appears that this was possible because of several factors including the following: a) The rules enable vendors to buy votes; $b$ ) The ballot was closed while 40 out of the 200 registered members of the ballot group have not yet cast their votes, and; c) The lack of transparency of the process which made it impossible to know the identity of members of the ballot group. The above has triggered procedural appeals at both the IEEE-SA and ANSI (American National Standards Institute) levels.

\section{DISCUSSION}

1) As mentioned above, space charge is one of the two main forces that govern development of the lightning channel. That charge is caused by the background radiation, corona on grounded objects and vegetation, space charges generated during actual discharge processes, space charges left over by previous discharges, the distribution of charge carriers, electrons, small and large ions, and the distributions thereof in combination with the violent atmospheric condition, different sorts of precipitation, and the extreme wind conditions experienced during thunder storms. As a result, the field distribution is far from the virgin environment that is presumed in the CVM.

2) The term "Collection Volume" is a misnomer as it implies that all strokes arriving within a certain volume/area will be collected by the structure. But that is not what Eriksson meant. Rather, the "Collection Volume" is the locus of the end points of the attractive radii for different values of the charge on the leader, i.e. different stroke amplitudes. Since the analysis of the shielding system is done for a single stroke amplitude, the concept of a combined parabolic locus complicated matters without serving any purpose.

3) As shown herein, the CVM is invalid. Hence it is inappropriate to describe it as an "improved EGM" [5]. 
It is more appropriate to describe it as a "chopped model" for having eliminated the ground plane. That omission appears to have partly arisen from not realizing that upward leaders can be induced from the ground plane, the same way that they are induced from structures.

4) ESE vendors use a single ESE device to protect a whole building. This practice is clearly both unsafe and inadequate regardless of whether ESE theory or the CVM is used to justify it.

5) It has been well publicized since 1999 that the scientific community at large opposes ESE systems [16]. Yet ERICO continued its aggressive promotion of its ESE devices without regard to the related safety concerns. This was initially justified by using ESE theory before switching to using the CVM.

6) ERICO previously claimed that both its design method and equipment have been validated by field data collected from installations in Malaysia and Hong Kong. That claim is obviously false in view the overwhelming evidence presented herein. In any case, Hartono [52] proved the invalidity of the readings of the lightning events counter upon which ERICO's study was based. Also, Hartono issued a report on case studies which elucidate the invalidity of the CVM [53]. Fig. (7) depicts one of those cases where lightning struck close to an ESE terminal that was placed in accordance with the CVM.

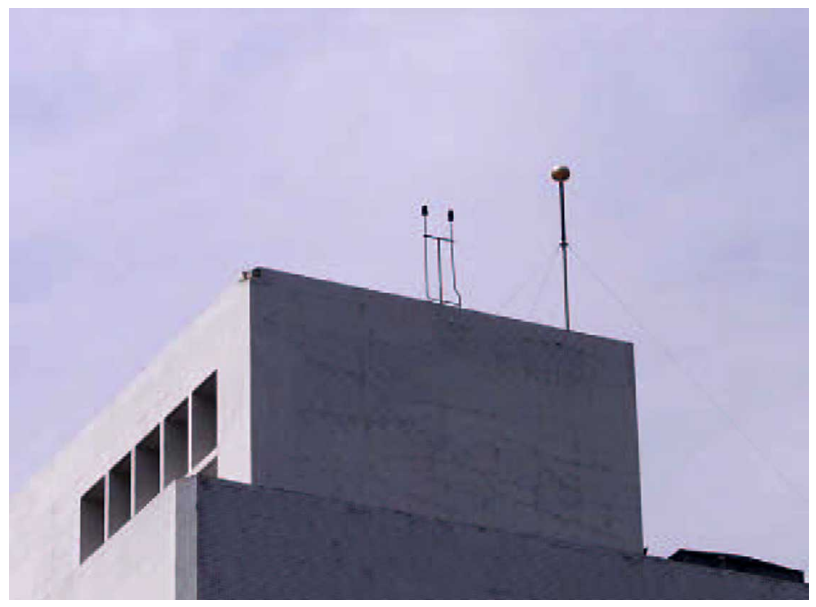

Fig. (7). Lightning strike to a point within $10 \mathrm{~m}$ of a Dynasphere placed in accordance with the CVM [19].

7) In defending the CVM, it has been argued that strikes to points below tops of structures only constitute a small percentage of the total collected strokes. That is no defense! For even a single incident would invalidate a theory if the theory predicts that such incidents cannot happen. In contrast, the EGM has a valid explanation for such strokes, and this can easily be seen by applying the Rolling Sphere Method, which is a simplified version of the EGM.

\section{CONCLUSIONS}

1) The commercial application of the CVM is nothing but an alternative method of justifying the unsafe practice of the vendors of ESE devices of using a single air terminal to protect a whole building. By switching to using the CVM, the vendors of ESE devices in USA and in Australia have in effect conceded that ESE theory is invalid.

2) In addition to the theoretical arguments previously raised by the scientific community against the CVM, its invalidity is proven by its discrepancies with field observations regarding the following: a) The assumptions upon which it is based, namely, its failure to take the effect of the space charge into consideration. b) Its estimates of the striking distance and the protective radius. c) Its predictions regarding extent of the shielding provided by an air terminal, especially the risk of strikes to the sides of tall structures. d) The construction of the model, namely the elimination of the ground plane, which appears to have partly resulted from not realizing that upward leaders are also generated from surface of the ground.

3) The objective of developing the CVM was to correct perceived shortcomings of the EGM that did not really exist, and the CVM actually suffers from those same shortcomings.

4) The claim that predictions of the CVM agreed with the observed performance of power lines is unjustified.

5) The vendors of ESE devices are seeking to legitimize them by getting the CVM sanctioned by standards organizations. They are now at an advanced stage of their attack against IEEE Standards Association after failing to penetrate the following organizations: IEC, Standards Australia and the NFPA.

6) It is hoped that intervention by the scientific community at large will make it possible to maintain the integrity of IEEE Standard 998.

\section{ACKNOWLEDGEMENT}

Declared none.

\section{CONFLICT OF INTEREST}

The author confirms that this article content has no conflicts of interest.

\section{REFERENCES}

[1] Young FS, Clayton JM, Hileman AR. Shielding of transmission lines. IEEE Trans Power Apparatus Syst 1963; S82: 132-54.

[2] Sargent M. The frequency distribution of current magnitudes of lightning strokes to tall structures. IEEE Trans Apparatus Syst 1972; PAS-91(5): 2224-9.

[3] Eriksson AJ. Lightning and tall structures. Trans S Afr IEEE 1978; 69(8): 238-52.

[4] Eriksson AJ. The incidence of lightning strikes to power lines IEEE Trans Power Deliv 1987; 2(3): 859-70.

[5] Eriksson AJ. An Improved electrogeometric model for transmission line shielding analysis. IEEE Trans Power Deliv 1987; 2(3): 87186 
[6] Anderson RB, Eriksson AJ. Lightning parameters for engineering application. Electra, 1980 March; 69: 65-102.

[7] Melander BG. Effects of Tower Characteristics on Lightning Arc Measurements. In: Proceedings of International Aerospace and Ground Conference on Lightning and Static Electricity. Paper no. 34. Orlando: Florida, USA 1984; p. 12.

[8] Ianoz M. Review of new developments in the modeling of lightning electromagnetic effects on overhead lines and buried cables. IEEE Trans Electromagn Compatibility 2007; 49(2): 22436.

[9] Mousa AM, Srivastava KD. Discussions of Eriksson's papers [11] and [12] above, IEEE Trans Power Deliv 1987; 2(3): 866-70 and 880-6.

[10] Mousa AM. Effect of height of structure on the striking distance of a downward lightning flash. In: Proceedings of International Communications and Energy Conference; IEEE Publication No. 84 CH 20412 REG7; 1984 Oct; Montreal: Quebec 1984; pp. 9-14.

[11] Mousa AM, Srivastava KD. The implications of the electrogeometric model regarding effect of height of structure on the median amplitude of collected lightning strokes. IEEE Trans Power Deliv 1989; 4(2): $1450-60$

[12] Mousa AM. A study of the engineering model of lightning strokes and its application to unshielded transmission lines. Ph.D. thesis. Vancouver, Canada:University of British Columbia, August 1986.

[13] Mousa AM, Srivastava KD. A revised electrogeometric model for the termination of lightning strokes on ground objects. In: Proceedings of International Aerospace and Ground Conference on Lightning and Static Electricity; April; Oklahoma City: Oklahoma 1988; pp. 34252 .

[14] Mousa AM. The frequency distribution of the amplitudes of lightning currents. Presented to the IEEE Task Force on Parameters of Lightning Strokes; 1994 July; San Francisco, California 1994; p. 6.

[15] Mousa AM, Wehling RJ. A survey of industry practices regarding shielding of substations against direct lightning strokes. IEEE Trans Power Deliv 1993; 8(1): 38-47.

[16] Mousa AM. Scientists oppose early streamer air terminals. [Updated $22^{\text {nd }}$ April 1999; cited $15^{\text {th }}$ April 2011]; Available from web site of National Lightning Safety Institute; www.LightningSafety.com, Section 5.4.3.

[17] Mousa AM. Validity of the collection volume method/field intensification method for the placement of lightning rods on buildings. In: Proceedings of the International Conference on Lightning Protection; paper no. 10a.4, 2002 Sept; Cracow, Poland; 2002; pp. 809-14.

[18] Mousa AM. Proposed research on the Collection Volume Method/Field Intensification Method for the placement of air terminals on structures. In: Proceedings of the IEEE-PES Annual Meeting; 2003 July; Toronto, Ontario; 2003; p.5.

[19] Hartono ZA, Robiah I. Performance of non-standard lightning air terminals: revisited. In: Proceedings of ICLP 2008; Uppsala: Sweden; 2008; p. 9

[20] D'Alessandro F, Gumley JR. A “Collection volume method" for the placement of air terminals for the protection of structures against lightning. J Electrostat 2001; 50: 279-302.

[21] Becerra M, Cooray V, Roman F. Lightning striking distance of complex structures. IET J Generation Transm Distribution 2008; 2(1): 131-8

[22] Bouquegneau $\mathrm{C}$. The lightning protection international standard. Invited lecture. In: Proceedings of International Conference on Lightning Protection; 2006 Sep; Kanazawa, Japan; 2006; p. 6.

[23] Pedersen AaE. Comments regarding air termination system for lightning protection systems positioning and efficiency. Letter to Committee EL 24, Standards Australia; 2002 February 4; p. 4.

[24] Pedersen AaE. Science, technology and standardization in lightning protection. International Conference on Lightning Protection; Cracow: Poland; Invited lecture 2002; p. 6.

[25] Rison W. Why the "Collection Volume Method" should not be incorporated into NFPA 780. Letter to NFPA, 2005, [cited: $20^{\text {th }}$ Feb 2012]; p. 6., Available from: http://tech.groups.yahoo.com/ group/LightningProtection/ Message/2434

[26] Schonland BFJ, Allibone TE. Branching of lightning. Nature 1931; 128(3236): 794-5.
[27] Szpor S. Lightning protective zones, IEEE PAS conference; paper no. A 78 513-4. 1978; p. 9.

[28] Golde RH. Lightning and tall structures. Proc IEE 1978; 125(4): 347-51.

[29] Rust WD, Moore CB. Electrical conditions near the bases of thunderclouds over New Mexico. Q J Royal Meteorol Soc 1974; 100: 450-68.

[30] Miki M, Miki T, Shimizu M. Observation of lightning flashes to transmission lines using a high speed camera system. In: Proceedings of International Conference on Lightning Protection; paper no. 1103; 2010; Cagliari: Italy; 2010; p. 6

[31] Anderson RB. Measuring techniques. In: Golde RH, Ed. Lightning, Volume 1, London, Britain: Academic Press 1977; pp. 437-63.

[32] Ambrose K. Photo of a lightning strike to the Washington Monument, Washington. DC, USA. 2005 [cited $15^{\text {th }}$ April 2011] Available from: http://epod.usra.edu.

[33] Golde RH. Lightning protection. London, Britain: Edward Arnold Publishing Company 1973; pp. 37-40.

[34] McComb TR, Linck H, Cherney EA, Janischewskyj W. Lightning research at the $\mathrm{CN}$ Tower in Toronto. In: Proceedings of Canadian Communications \& Power Conference; IEEE Publication No. 78 CH 1373-0 REG 7. 1978; pp. 345-48.

[35] Gorin BN, Levitov VI, Shkilev AV. Lightning strokes to Ostankino TV tower in Moscow. Electric Technology USSR 1977;(3): 45-55.

[36] Krider EP, Alejandro SB. Lightning - an unusual case study. Weatherwise 1983 April; 36(2): 71-75.

[37] Uman MA. The Lightning discharge. New York, NY: Academic Press 1987; pp. 106 and 103

[38] Cooray V. On the upper and lower limit of peak current in first return strokes of lightning flashes. In: Proceedings of International Conference on Lightning Protection; 2010; paper no. 1291, Cagliari: Italy; 2010; p.7.

[39] Krider EP, Cummins KL, Biagi CJ, Fleenor SA, Wilson JG. Small negative strokes in cloud-to-ground lightning flashes. In Proceedings of International Conference on Lightning Protection; paper no. 1387, Cagliari, Italy; 2010; p.3.

[40] McEachron KB. Lightning to the Empire State Building. J Franklin Inst $1939 \mathrm{Feb} ; 227(2): 149-217$, at page 201.

[41] Golde RH. Occurrence of upward streamers in lightning discharges. Nature 1947; 160(4064): 395-6.

[42] Krider EP, Ladd CG. Upward streamers in lightning discharges to mountainous terrain. Weather 1975; 30: 77-81.

[43] Warner TA. Observations of simultaneous multiple upward leaders from tall structures. In: Proceedings of International Conference on Lightning Protection; paper no. 1070; Cagliari: Italy 2010; p. 3.

[44] Whitehead ER. Final report on mechanism of lightning flashover research project. Final Report. Publication No. 72-900; New York, NY: Edison Electric Institute 1971; p. 84.

[45] Mazur V, Ruhnke LH, Bondiou-Clergerie A., Lalande P. Computer simulation of a downward negative stepped leader and its interaction with a ground structure. J Geophys Res 2000; 105(D17): 22361-9.

[46] Mazur V, Ruhnke LH. Evaluation of the Lightning Protection System at the WSR-88D Radar Sites. Norman, Oklahoma: A report prepared for the US National Weather Service by staff of the National Severe Storms Laboratory, May 2001.

[47] Dellera L, Garbagnati E. Lightning stroke simulation by means of the leader progression model: Parts I and II. IEEE Trans Power Deliv 1990; 5(4): 2009-29.

[48] Rizk FAM. Modeling of transmission line exposure to direct lightning strokes. IEEE Trans Power Deliv 1990; 5(4): 1983-97.

[49] Becerra M, Cooray V. A Self-consistent upward leader propagation model. J Phys D Appl Phys 2006; 39: 3708-15.

[50] Mazzetti C. Comments on the collection volume method/field intensification method. Letter from the Scientific Committee of International Conference on Lightning Protection to Standards Australia, Sep 8, 2002.

[51] Mazzetti C. Letter from the Scientific Committee of International Conference on Lightning Protection to the administration of NFPA, Feb 18, 2003. 
[52] Hartono ZA, Robiah I. Case studies on the performance of commercial-grade lightning event counters. In: Proceedings of Asia Pacific EMC Symposium; 2008 May; Singapore; 2008; pp. 486-9. Available from: http://tinyurl.com/chwhh5.
[53] Hartono ZA, Robiah I. Case Studies on the Collection Volume Method. 2010 [cited 15 $5^{\text {th }}$ April 2011]. p. 15. Available from: http://tech.groups.yahoo.com/group/LightningProtection/Message\# 2213

Received: April 15, 2011

Revised: December 30, 2011

Accepted: January 5, 2012

(C) Abdul M. Mousa; Licensee Bentham Open.

This is an open access article licensed under the terms of the Creative Commons Attribution Non-Commercial License (http://creativecommons.org/licenses/by-nc/3.0/) which permits unrestricted, non-commercial use, distribution and reproduction in any medium, provided the work is properly cited. 